\title{
ANALISIS KREATIVITAS METAKOGNISI MAHASISWA BERDASAR ADVERSITY QUOTIENT (AQ) DALAM MENYELESAIKAN MASALAH YANG BERKAITAN DENGAN APLIKASI KONSEP KALKULUS
}

\author{
Kamid \\ Dosen Program Studi Pendidikan Matematika Universitas Jambi \\ e-mail:mas_gaya@yahoo.com
}

\begin{abstract}
Abstrak
Metakognisi adalah kesadaran individu tentang hasil pemikirannya. Penting bagi pendidik untuk mengetahui hal ini, agar dapat diberikan stimulus sesuai dengan kadar intelektualitasnya. Kreativitas metakognisi merupakan kesadaran individu tentang prosedur-prosedur metakognisi terhadap kebaruan dan kompleksitanya. Hal ini dapat diungkap dari perilaku yang ditampilkan dan ucapan yang disuarakan.

Penelitian kualitatif eksploratif ini mengungkap kreativitas metakognisi dari mahasiswa berdasarkan Advesity Quoitient (AQ) yang bertipe climber. dalam menyelesaikan masalah benda bergerak. Eksplorasi dilakukan pada seorang subjek dengan think alouds dan wawancara. Kredibilatas data dilakukan dengan triangulasi waktu.

Hasil penelitian menunjukkan bahwa sesuai dengan karakteristik climber dalam AQ menunjukkan bahwa subjek selalu dapat memberikan alasan pada langkah dan algoritma yang dilakukan. Prosedur aritmatika, digunakan dengan merespon prosedur dan memikirkan keakuratan nilai dan operasi yang digunakan. Subjek dapat memberi alasan ketika hasil perhitungan diluar kebiasaan yang terjadi dikehidupannya.
\end{abstract}

Kata kunci: kreativitas metakognisi, climber, benda bergerak

\begin{abstract}
Abstrac
Metacognition is the awareness of individuals about the results of his thinking. It is important for educators to know that, in order to be given according to the level of intellectual stimulus. Creativity metacognition is the awareness of individuals about the procedures of the novelty and complexity metacognition. It can be revealed from the behavior displayed and voiced speech.

This exploratory qualitative study reveals the creativity of student metacognition by Adversity Quotient (AQ) of type climber. in solving the problem of moving objects. Exploration conducted on a subject with think louds and interviews. The credibility of the data is done by triangulation time.

Results showed that according to the characteristics of the climber in the AQ showed that subjects can always give a reason in steps and algorithms are performed. Arithmetic procedures, the procedures used to respond to and think about the value accuracy and operational use. Subject to the results of the calculations gives them an excuse when out of the ordinary is happening around him.
\end{abstract}

Keywords: creativity metacognition, climber, moving objects

Analisis Kreatifitas.................................................................... 


\section{A. PENDAhULUAN}

Metakognisi secara umum berkaitan dengan dua dimensi berpikir, yaitu (1) selfawareness of cognition, yaitu kesadaran yang dimiliki seseorang tentang berpikirnya, dan (2) self-regulation of cognition, yaitu kemampuan seseorang menggunakan kesadarannya untuk mengatur proses berpikirnya (Bruning, Schraw dan Ronning, 1995). Kedua dimensi metakognisi tersebut memiliki sifat interdependen yaitu saling bergantung satu dengan lainnya.

Penelitian-penelitian tersebut tidak melihat bagaimana proses metakognisi terjadi. Penelitian tersebut juga belum mengungkapkan metakonisi apabila subjek penelitian dikelompokkan menurut kategori tertentu.

Pemahaman tentang proses berpikir sangat perlu dalam pembelajaran Kalkulus, terutama bagi dosen. Hal ini dimaksudkan agar setiap pembelajaran yang dilakukan selalu memperhatikan kemampuan berpikir Matematika mahasiswa. Dengan demikian strategi, media, dan materi pembelajaran dapat dipilih dan disesuaikan. Sesuai dengan hal itu, Tate dan Johnson (1999) menegaskan bahwa salah satu indikator dosen Matematika yang berkualitas adalah bagaimana baiknya dosen memahami proses berpikir dan penalaran mahasiswa tentang Matematika dan bagaimana memperluas kemampuan mereka tersebut.

Hasil survei yang dilakukan terhadap mahasiswa, ternyata materi aplikasi turunan dalam kalkulus khususnya benda bergerak sangat sulit dipahami. Hasil wawancara menunjukkan bahwa sebagian besar mereka tidak secara sungguh-sungguh ingin memahami materi tersebut. Sebagian lagi menyatakan bahwa materi benda bergerak terasa sudah di depan mata, tetapi sulit untuk diterangkan. Beradasarkan hasil ini, dapat disimpulkan bahwa pengetahuan metakognisi mahasiswa belum optimal.meraka cenderung menghafal dan tidak melakukan pemikiran yang mendalam. Oleh karena itu mahasiswa harus dapat melakukan dan menerapkan kemampuan metakognisi setiap proses pemecahan masalah yang dihadapi.

Terdapat beberapa definisi tentang metakognisi yang berkembang dalam bidang psikologi kognitif, diantaranya Flavell (Lee dan Baylor, 2006), Panaoura dan Philippou (2001), Brown (Lee dan Baylor, 2006)mendefinisikan: metakognisi sebagai kemampuan untuk memahami dan memantau berpikirnya sendiri dan asumsi serta implikasi kegiatan seseorang. Metacognition as the ability to understand and monitor one's own thoughts and the assumptions and implications of one's activities. Pendapat ini menekankan metakognisi sebagai kemampuan untuk memahami dan memantau kegiatan berpikir, sehingga proses metakognisi tiap-tiap orang akan berbeda menurut kemampuannya.

Brown (Lee dan Baylor, 2006) dan Stevens (2000) secara khusus membatasi empat komponen, dari metakognisi yaitu: perencanaan, pemantauan, pengevaluasian, dan perevisian. Pada bagian lain, Cohors-Fresenborg dan Kaune (2007) merangkum komponen-komponen metakognisi ke dalam tiga aktivitas metakognisi yang dilakukan pada pemecahan masalah, terdiri dari: (1) merencanakan (planning), (2) memantau (monitoring), dan (3) refleksi (reflection).

Menurut Tobias dan Everson (Gama, 2004), pemantauan terhadap belajar sebelumnya adalah proses metakognitif dasar atau prasyarat. Flavell (1979) menjabarkan tiga jenis pengetahuan metakognitif dari seorang individu yaitu : 1) Awareness of knowledge, 2) Awareness of thinking,3) Awareness of thinking strategies. Sementara itu Ann Herrmann (2010) memberikan pengertian tentang berpikir kreatif 
yaitu understood as a series of thinking processes that can be applied and learned, it suddenly becomes available to us all.

Ann Herrmann (2010) memberikan batasan tentang berpikir kreatif yaitu: 1) Anticipate future events and issues; 2) Create alternative scenarios; 3) Understand your options; 4) Decide on your objectives; 5) Determine the direction to achieve those objectives on a winning basis. Berkaitan hal itu, Gonzales (2001) menyatakan bahwa krativitas seseorang harus memenuhi tiga unsur yaitu orisinalitas, ketepatan dan relevansi dalam hasil dan penggunaannya.

Selain metakognisi, suksesnya pekerjaan dan hidup seseorang banyak ditentukan oleh $A Q$. Orang yang memiliki $A Q$ lebih tinggi mampu berpikir, bertindak, dan menyiasati diri untuk menyelesaikan masalahnya. Sebaliknya rendahnya $A Q$ seseorang menyebabkan mudah mengeluh dan mudah berputus asa serta menyerah pada nasib. Sebagaimana yang diungkapkan oleh Stolzt (2000:185) yaitu semakin rendah AQ seseorang, semakin rendah orang itu menyerah pada nasib.

Stoltz (2000:138-139) mengelompokkan orang ke dalam tiga kategori $A Q$, yaitu: quitter ( $A Q$ rendah), camper ( $A Q$ sedang), dan climber ( $A Q$ tinggi). Stoltz (2000) menggunaaan istilah quitter, camper, dan climber. Stoltz mengistilahkan orang yang berhenti di tengah jalan sebelum usai sebagi quitter, kemudian mereka yang merasa puas berada pada posisi tertentu sebagai camper, sedangkan yang terus ingin sukses sampai ke puncak kesuksesan disebut climber.

Tujuan penelitian ini adalah untuk mendapat deskripsi dan analisis yang lengkap tentang kreativitas metakognisi mahasiswa berdasarkan Adversity Quotient tipe climber dalam menyelesaikan masalah yang berkaitan dengan benda bergerak. Secara khusus mendeskripsikan tentang proses metakognisi dalam: Persiapan, Inkubasi, Iluminasi, dan Verifikasi

\section{B. METODE PENELITIAN}

Penelitian kualitatif ini menggunakan subjek yang dipilih melalui tes ARP sebanyak satu orang yang memenuhi kategori Climber. Menurut Stoltz (2000). Subjek melalukan think loud ketika menyelesaikan masalah pergerakan benda dan diikuti wawancara seperlunya jika peneliti merasa tidak paham. Hasil think loud ditranskripsi segera dan dilakukan secara berulang agar tidak terjadi bias. Triangulasi waktu dilakukan untuk memperoleh data yang kredibel. Data dianalisis dengan memberi kode untuk kategori kreativitas metakognisi tertentu. Kesimpulan diambil dari penafsiran kode yang dieproleh dengan pedoman instrumentasi yang ditetapkan.

\section{HASIL PENELITIAN DAN PEMBAHASAN}

Data hasil penelitian yang dipaparkan adalah data yang berhasil dikumpulkan dan telah dilakukan reduksi. Untuk memudahkan membaca data, tampilan data diklasifikasikan menurut urutan yang logis.

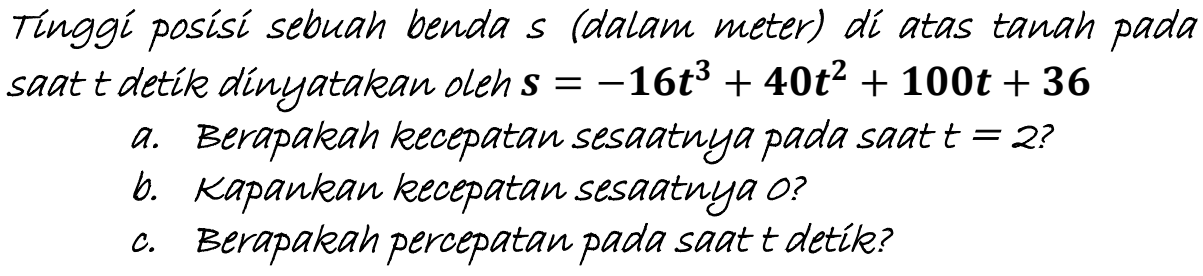




\section{Persiapan}

\begin{tabular}{|c|c|}
\hline Metakognisi & Kreativitas pemecahan masalah \\
\hline $\begin{array}{l}\text { - Sadar terhadap proses dan hasil } \\
\text { berpikirnya, dalam mengembangkan } \\
\text { perencanaan, saat memahami masalah } \\
\text { - Sadar terhadap proses dan hasil } \\
\text { berpikirnya, dalam memonitor } \\
\text { informasi yang dimiliki dan } \\
\text { digunakan. } \\
\text { - Sadar terhadap proses dan hasil } \\
\text { berpikirnya, dalam mengevaluasi } \\
\text { pengetahuan prasyarat. }\end{array}$ & $\begin{array}{l}\text { Setelah membaca soal itu, saya tahu bahwa soal itu } \\
\text { sudah memuat persamaan lintasan benda bergerak. } \\
\text { Dari persamaan lintasan itu saya mengetahui bahwa } \\
\text { lintasannya tidak linear, sehingga kemungkinan ada } \\
\text { percepatan yang dapat dihitung. Dari pertanyaan } \\
\text { yang diberikan, saya tahu bahwa semuanya berkaitan } \\
\text { dengan benda bergerak, mulai kecapatan rata-rata, } \\
\text { kecepatan sesaat, benda berhenti bahkan percepatan } \\
\text { yang yang mungkin dapat dihitung pada saat } \\
\text { tertentu. }\end{array}$ \\
\hline
\end{tabular}

2. Inkubasi

\begin{tabular}{|l|l|}
\hline \multicolumn{1}{|c|}{ Metakognisi } & \multicolumn{1}{|c|}{ Kreativitas pemecahan masalah } \\
\hline - Berhenti sejenak ketika menemukan \\
$\begin{array}{l}\text { kesulitan dan melakukan aktivitas- } \\
\text { aktivitas lain. }\end{array}$ & $\begin{array}{l}\text { Ini agak sulit..., tapi saya coba dengan pengetahuan } \\
\text { yang saya miliki. Saya tahu bahwa ini menggunakan } \\
\text { konsep turunan yaitu turunan pertama dan turunan } \\
\text { kedua. Tetapi terus bagaimana ya...? }\end{array}$ \\
\hline
\end{tabular}

\section{Iluminasi}

\begin{tabular}{|l|l|}
\hline \multicolumn{1}{|c|}{ Metakognisi } & \multicolumn{1}{|c|}{ Kreativitas pemecahan masalah } \\
\hline $\begin{array}{l}\text { Menemukan lebih dari satu jawaban } \\
\text { benar dan cara penyelesaiannya serta } \\
\text { menggunakannya pada pemecahan } \\
\text { masalah. }\end{array}$ & $\begin{array}{l}\text { Pertama-tama saya gambar saja lintasan dan gerak } \\
\text { bendanya, tetapi kok ada yang arah ke kiri? Dari titik- } \\
\text { titik yang saya hubungkan arah lintasan ke kanan dan } \\
\text { sebagian ke kiri dan ke kanan lagi. Gimana nih...? coba } \\
\text { dengan cara turunan, ternyata nilai turunan pertama } \\
\text { pada titik tertentu negatif dan yang lain positif. Oh... ini } \\
\text { menunjukkan pada waktu tertentu benda itu bergerak } \\
\text { maju dan pada rentang waktu tertentu mundur, itu tadi } \\
\text { yang bergerak ke kiri. Ternyata } \frac{d y}{d x} \text { ada yang positif dan } \\
\text { ada yang negatif. } \\
\text { Untuk menentukan percepatan benda, ternaya tidak bisa } \\
\text { digambarkan. Salah satu cara adalah dengan } \\
\text { menggunakan turunan kedua dari persamaan lintasan } \\
\text { yaitu } \frac{d^{2} y}{d x^{2}} . \text { Dari perthitungan yang saya lakukan } \\
\text { diperoleh percepatan benda bergerak pada saat t yang } \\
\text { ditanyakan. }\end{array}$ \\
\hline
\end{tabular}

\section{Verifikasi}

\begin{tabular}{|l|l|}
\hline \multicolumn{1}{|c|}{ Metakognisi } & \multicolumn{1}{|c|}{ Kreativitas pemecahan masalah } \\
\hline $\begin{array}{l}\text { Memeriksa kembali setiap jawaban } \\
\text { yang diperoleh. }\end{array}$ & $\begin{array}{l}\text { Saya sudah berusaha sekuat tenaga menyelesaikan soal } \\
\text { yang diberikan, tetapi tidak ada salahnya kalau jawaban } \\
\text { dan langkah-langkah yang saya lakuikan saya periksa }\end{array}$ \\
& $\begin{array}{l}\text { sekali lagi. Langkah-langkah yang saya lakukan saya } \\
\text { periksa satu persatu. Saya merasa tidak mendapatkan }\end{array}$ \\
& $\begin{array}{l}\text { keganjilan. Tetapi apakah jawaban saya benar? Saya } \\
\text { coba-coba cocokan dengan soal yang diberikan, }\end{array}$ \\
& ternyata saya juga tidak menemukan hasiil yang \\
\hline
\end{tabular}




\section{Analisis Data}

berbeda. Saya semakin yakin dengan jawaban saya, tidak ada jalan laian dan jawaban lain selain yang saya berikan.

Analisis data yang dilakukan adalah menentukan klasifikasi proses kreatif metakognisi. Analisis dilakukan dengan menandai setiap proses dengan sebuah kode yang unik. Kode-kode ini merupakan satuan yang dapat ditafsirkan sebagi kreativitas metakognisi.

1. Persiapan

\begin{tabular}{|c|c|c|}
\hline Metakognisi & Kreativitas pemecahan masalah & Koding \\
\hline \multirow{4}{*}{$\begin{array}{l}\text { - Sadar terhadap proses } \\
\text { dan hasil berpikirnya, } \\
\text { dalam } \\
\text { mengembangkan } \\
\text { perencanaan, saat } \\
\text { memahami masalah } \\
\text { - Sadar terhadap proses } \\
\text { dan hasil berpikirnya, } \\
\text { dalam memonitor } \\
\text { informasi yang dimiliki } \\
\text { dan digunakan. } \\
\text { - Sadar terhadap proses } \\
\text { dan hasil berpikirnya, } \\
\text { dalam mengevaluasi } \\
\text { pengetahuan prasyarat. }\end{array}$} & $\begin{array}{l}\text { Setelah membaca soal itu, saya tahu bahwa soal itu sudah } \\
\text { memuat persamaan lintasan benda bergerak. }\end{array}$ & MPDt \\
\hline & $\begin{array}{l}\text { Dari persamaan lintasan itu saya mengetahui bahwa } \\
\text { lintasannya tidak linear, sehingga kemungkinan ada } \\
\text { percepatan yang dapat dihitung. }\end{array}$ & MPSy \\
\hline & $\begin{array}{l}\text { Dari pertanyaan yang diberikan, saya tahu bahwa } \\
\text { semuanya berkaitan dengan benda bergerak, }\end{array}$ & MPSy \\
\hline & $\begin{array}{l}\text { mulai kecapatan rata-rata, kecepatan sesaat, benda berhenti } \\
\text { bahkan percepatan yang mungkin dapat dihitung pada saat } \\
\text { tertentu. }\end{array}$ & MPDt \\
\hline
\end{tabular}

Keterangan:

MPDt : Memahami data pada langkah persiapan

MPSy : Memahami syarat pada langkah persiapan

2. Inkubasi

\begin{tabular}{|c|c|c|}
\hline Metakognisi & Kreativitas pemecahan masalah & Koding \\
\hline \multirow{3}{*}{$\begin{array}{l}\text { Berhenti sejenak ketika } \\
\text { menemukan kesulitan } \\
\text { dan melakukan aktivitas- } \\
\text { aktivitas lain. }\end{array}$} & $\begin{array}{l}\text { Ini agak sulit..., tapi saya coba dengan pengetahuan yang } \\
\text { saya miliki. }\end{array}$ & IMP \\
\hline & $\begin{array}{l}\text { Saya tahu bahwa ini menggunakan konsep turunan yaitu } \\
\text { turunan pertama dan turunan kedua. }\end{array}$ & IMC \\
\hline & Tetapi terus bagaimana ya...? & IMC \\
\hline
\end{tabular}

Keterangan:

IMP : inkubasi memahami pengetahuannya

IMC : inkubasi memahahi cara menyelesaikan

3. Iluminasi

\begin{tabular}{|c|c|c|}
\hline Metakognisi & Kreativitas pemecahan masalah & Koding \\
\hline \multirow{3}{*}{$\begin{array}{l}\text { Menemukan lebih dari } \\
\text { satu jawaban benar dan } \\
\text { cara penyelesaian nya } \\
\text { serta mengguna kannya } \\
\text { pada pemecah an } \\
\text { masalah. }\end{array}$} & $\begin{array}{l}\text { Pertama-tama saya gambar saja lintasan dan gerak } \\
\text { bendanya, tetapi kok ada yang arah ke kiri? }\end{array}$ & LCS \\
\hline & $\begin{array}{l}\text { Dari titik-titik yang saya hubungkan arah lintasan ke kanan } \\
\text { dan sebagian ke kiri dan ke kanan lagi. }\end{array}$ & LCS \\
\hline & $\begin{array}{l}\text { Gimana nih...? coba dengan cara turunan, ternyata nilai } \\
\text { turunan pertama pada titik tertentu negatif dan yang lain }\end{array}$ & ILCS \\
\hline
\end{tabular}




\begin{tabular}{|l|l|l|}
\hline positif. & \\
\hline $\begin{array}{l}\text { Oh... ini menunjukkan pada waktu tertentu benda itu } \\
\text { bergerak maju dan pada rentang waktu tertentu mundur, } \\
\text { itu tadi yang bergerak ke kiri. }\end{array}$ & LCS \\
\hline $\begin{array}{l}\text { Ternyata } \frac{d y}{d x} \text { ada yang positif dan ada yang negatif. } \\
\text { Untuk menentukan percepatan benda, ternyata tidak bisa } \\
\text { digambarkan. }\end{array}$ & LCS \\
\hline $\begin{array}{l}\text { Salah satu cara adalah dengan menggunakan turunan } \\
\text { kedua dari persamaan lintasan yaitu } \frac{d^{2} y}{d x^{2}} .\end{array}$ & LCS \\
\hline $\begin{array}{l}\text { Dari perhitungan yang saya lakukan diperoleh percepatan } \\
\text { benda bergerak pada saat t yang ditanyakan. }\end{array}$ & LCS \\
\hline
\end{tabular}

Keterangan:

LCS : Ilmuninasi cara penyelesaian

ILCS : Inkubasi cara penyelesaian

4. Verifikasi

\begin{tabular}{|l|l|l|}
\hline \multicolumn{1}{|c|}{ Metakognisi } & \multicolumn{1}{|c|}{ Kreativitas pemecahan masalah } & koding \\
\hline $\begin{array}{l}\text { Memeriksa } \\
\text { kembali setiap } \\
\text { jawaban yang } \\
\text { diperoleh. }\end{array}$ & $\begin{array}{l}\text { Saya sudah berusaha sekuat tenaga menyelesaikan soal yang } \\
\text { diberikan, }\end{array}$ & VPS \\
\cline { 2 - 3 } & $\begin{array}{l}\text { tetapi tidak ada salahnya kalau jawaban dan langkah-langkah yang } \\
\text { saya lakuikan saya periksa sekali lagi. }\end{array}$ & VSA \\
\cline { 2 - 3 } & Langkah-langkah yang saya lakukan saya periksa satu persatu. & VPS \\
\cline { 2 - 3 } & $\begin{array}{l}\text { Saya merasa tidak mendapatkan keganjilan. Tetapi apakah } \\
\text { jawaban saya benar? }\end{array}$ & VSA \\
\cline { 2 - 3 } & $\begin{array}{l}\text { Saya coba-coba cocokan dengan soal yang diberikan, ternyata } \\
\text { saya juga tidak menemukan hasiil yang berbeda. }\end{array}$ & VPS \\
\cline { 2 - 3 } & $\begin{array}{l}\text { Saya semakin yakin dengan jawaban saya, tidak ada jalan laian } \\
\text { dan jawaban lain selain yang saya berikan. }\end{array}$ & VPS \\
\hline
\end{tabular}

Keterangan:

VPS : Verifikasi prosedur penyelesaian

VSA : Verifikasi penyelesaian akhir

\section{Pembahasan}

Pemahamannya terhadap data dan syarat sebuah soal dilakukannya dengan mudah. Menurut van Someren dkk (1994). Data yang dipergunakan sudah berada pada short term memory (STL) yang kemudian dengan mudah dapat diubah menjadi protokol. Protokol-protokol yang muncul (MPDt dan MPSy) hanyalah pemanggilan pengetahuan yang sudah siap untuk digunakan.

Prosedur penyelesaian yang dilakukan hanya prosedur rutin. Kreativitas metakognisi yang dimunculkan hanya pada level sederhana karena tidak memuat unsur kebaruan. Kompleksitas prosedur dan hasil yang diperoleh juga menunjukkan kesederhanaan. Rutinitas prosedur yang dilakukan mengarah pada hasil yang rutin juga. Hal ini dapat dilihat penggunaan gambar dan turunan yang dilakukan untuk menyelesaikan permasalahan.

Hasil penelitian menunjukkan bahwa kerangka kerja Stevens (2000), tentang kreativitas metakognisi subjek hanya rutinitas prosedur penyelesaian soal. Subjek hanya ngan mendapat memberikan penyelesaian yang berbeda pada cara penyelesaian masalah yaitu dengan gambar dan konsep tururan (LCS). Subjek sangat memahami penggunaan 
turunan $\frac{d y}{d x}$ untuk menghitung kecepatan dan turunan kedua $\frac{d^{2} y}{d x^{2}}$ untuk menghitung percepatan (LCS).

Berdasarkan hasil penelitian juga diketahui bahwa kreativitas metakognisi tidak muncul dalam setiap langkah penyelesaian. Metakognisi muncul hanya sekedar sadarnya subjek terhadap setiap langkah penyelesaian. Kesadaran yang dimaksud (metakognisi) adalah adanya alasan setiap langkah penyelesaian masalah benda bergerak.

\section{KESIMPULAN DAN SARAN}

\section{Kesimpulan}

Berdasarkan hasil penelitian, dapat dismpulkan sebagai berikut:

a. Preparation, data yang diungkapkan sebagai data rutin yang seharusnya memang muncul dalam penyelesaian soal matematika khususnya tentang benda bergerak.

b. Inkubasi, pengendapan pengetahuan yang diterima dan pencocokan pengetahuan yang digunakan dilakukan dari short term memory, artinya pengetahuan yang sudah siap dijadikan protokol.

c. Iluminasi, metode yang digunakan hanya dua dan tidak variatif dan prosedur rutin yang diogunakan daalam menyelesaikan soal benda pergerak khususnya menghitung kecepatan dan percepatan.

d. Verifikasi, subjek melakukan pengecekakan prosedur dan hasil akhir. Subjek dapat dengan lancar memeriksa setiap prosedur dan hasil. Semua langkah yang dilakukan disadari merupakan pilihan yang paling benar.

\section{Saran}

Kesimpulan yang diuraikan, mengarah pada saran-saran sebagai berikut:

a. Matekognisi hendaknya diajarkan di sekolah menengah dalam setiap penyelesaian soal yang diberikan.

b. Penelitian ini tidak mengungkap proses penyerapan informasi yang kemudian dimunculkan sebagai metakognisi, oleh karena itu perlu adanya penelitian yang mengungkap hal tersebut.

c. Adanya penelitian lanjutan yang mengeksplorasi kreativitas metakognisi pad Adversity Quotient tipe lain, sehingga hasilnya saling melengkapi.

\section{DAFTAR PUSTAKA}

Gama, C., (2004). Integrating Metacognition Instruction in Interactive Learning Environments. Submitted for the degree of D. Phil. http://www.dcc.utba. br/ claudiag/thesis/index_Gama.pdf. Diakses tanggal 20 Maret 2012.

Johnson, E. B., 2002, Contextual Teaching and Learning; What It is and Why It's Here to Stay, Corwin Press Inc., California 
Lee, M., and Baylor, A. L., 2006, Designing Metacognitive Maps for Web-Based Learning, Educational Technology \& Society, 9 (1), 344 - 348

Panaoura, A., and Philippou, G., 2001, Young Pupils' Metacognitive Abilities in Mathematics in Relation to Working Memory and Processing Efficiency, www.ucy.ac.cy, Diakses tanggal 12 November 2007

Panaoura, A., and Philippou, G., 2005, The Measurement of Young Pupils' Metacognitive Ability in Mathematics: The Case of Self-Representation and Self-Evaluation, www.ucy.ac.cy, Diakses tanggal 12 November 2007.

Purcell, E.J. 2000. Calculus with Analytic Geometry. New York. Jhon Wiley \& Sons.

Riduwan, Drs, M.B.A, 2009. Belajar Mudah Penelitian untuk Guru, Karyawan dan Peneliti Pemula. Bandung: Alfabeta.

Satori, Djam'an Prof. Dr dan Komariah, Aan M.Pd Dr. 2010. Metodologi Penelitian Kualitatif. Bandung : Alfabeta.

Stevens, V. 2000. The Importance of Creativity, Emotional Intelligence and the Arts for Education in the $21^{\text {st }}$ Century. Presented at the National Academy of Recording Arts and Sciences

Stoltz, P. G. 2000. Adversity Quotient: Mengubah Hambatan Menjadi Peluang. Terjemahan oleh: T. Hermaya. Jakarta: PT. Gramedia Widiasarana Indonesia.

Sudarman. 2010. Proses Berpikir Siswa SMP Berdasarkan Adversity Quotient (AQ) dalam Menyelesaikan Masalah Matematika. http://www.lontar.ui.ac.id/opac/themes/libri2/detail.jsp?id=134115\&lokasi=

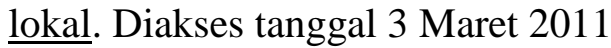

Sugiyono, 2009. Metode Penelitian Kuatitatif, Kualitatif dan R\&D. Bandung: Alfabeta.

Tobias, S., Everson, H. T., Laitusis, V., and Fields, M., 1999, Metacognitive Knowledge Monitoring: Domain Specific or General, Paper Presented at the Annual Meeting of the Society for the Scientific Study of Reading in a Symposium.

Van Someren, Marteen W., Barnard, Yvonne F., dan Sandberg, Jacobin A.C. 1994. The Think Aloud Method. A Practical guide to modelling cognitive processes. London. Academic Press. 